\title{
Psychiatric discharge summaries in the South East Thames region
}

\author{
B. Essex, General Practitioner, Sydenham Green Health Centre, 26 Holmshaw Close, \\ London SE26 4TG; and J. RoseNTHAL, Lecturer in General Practice, Royal Free \\ Hospital Medical School, London NW3 2QG
}

Patients discharged after acute psychiatric admission are vulnerable, and need continuing care in the community. For these people and their families, the first two weeks after discharge is a critical time. This is when problems arise, support is needed, drugs run out, and default most likely. Care may be shared between psychiatrist, community psychiatric nurse, general practitioner and other health personnel. It is therefore essential to identify the roles and responsibilities of all involved in follow-up care. Studies have shown that information needed by general practitioners includes differential diagnosis, management, treatment on discharge, prognosis, what patient and relatives were told, future plans which specify the roles and responsibilities of all involved, as well as the date of any follow-up appointment. Moreover this information is needed within two weeks of discharge. Without this information effective follow-up is unlikely to occur. The early discharge summary provides this vital information in the immediate post-discharge period. This is quite distinct from the final report which usually takes a few weeks to be sent. It is therefore important to identify current psychiatric practice relating to the initial discharge summary.

\section{The study}

\section{Objectives}

A survey was undertaken of all psychiatrists caring for patients admitted to acute psychiatric units in the South East Thames Region. The objectives of this study were to identify:

whether or not early discharge summaries are sent to general practitioners

what information is provided

whether patients are given a copy to take to their general practitioner

the reasons why some psychiatrists do not send initial discharge summaries

supplies of drugs given on discharge estimates of the time taken for final reports to reach general practitioners

the types of early discharge summaries used throughout the region.
In November 1989 a postal questionnaire was sent to all the psychiatrists working in acute psychiatric units within the South East Thames Region. These were identified from the Medical Directory. Each unit was phoned to confirm that it dealt with acute psychiatric patients below 65 years of age and to update the list of consultants. The questionnaire was sent to all 72 consultants working in the 21 acute psychiatric units within the region. They were also asked to enclose copies of the early discharge summary if one was used.

\section{Findings}

Responses were obtained from one or more psychiatrists working in each of the 21 acute units. Of the 72 psychiatrists, 51 responded $(71 \%)$.

Early discharge summaries were not sent by $22 \%$ of consultants. This included one consultant from each of the major teaching hospitals in the region. When the need has been so clearly established it is surprising to find that many psychiatrists believe the discharge summary is unnecessary. The information needs of general practitioners do seem to be recognised by all respondents. However, the reasons given for not sending summaries included:

lack of staff and secretarial help

not departmental policy

key workers can be contacted by patient clinically ill patients can come to the clinic general practitioners are not interested liaison via community psychiatric nurses to general practitioners is enough the final report is adequate.

Many of the responses suggest a low perception of the role of the family doctor after hospital discharge.

If each of the 11 psychiatrists who do not send summaries averaged 150 admissions a year, 1750 patients a year would be discharged without any immediate information provided for their family doctors.

Of the psychiatrists, $16 \%$ gave discharge medication for less than seven days; $78 \%$ gave medication for between seven and 14 days. Yet all estimated that it would take some weeks for the final report to 
arrive. Most patients on long-term medication need follow-up, but not all will be given out-patient clinic appointments or see the community psychiatric nurse: For many, it is the general practitioner who will have to provide long-term care. Yet effective continuity is made very difficult by the lack of essential information about treatment and future management plans.

It is essential for the general practitioner to be informed about treatment as soon as possible after discharge. Giving patients the discharge summary to take to their doctor has been shown to be the quickest way to achieve this goal. It is therefore disappointing to discover that only $25 \%$ of respondents gave copies to their patients to take to their doctor. Compliance may be better than many would think, and some patients may bring their copy to the doctor before the postal copy arrives. This may be critical when patients are given medication for less than seven days.

Junior staff are rarely trained in the skills needed to write a good discharge summary. Many have expressed a preference for pro formas which were designed to help doctors to record the most relevant information.

This survey has revealed a bewildering variety of summaries in current use, most of which provide the basic minimum of diagnosis and medication only. The one used by the Maidstone and Eastbourne group of hospitals seemed very comprehensive and useful. Most GPs now consider that an early discharge summary is a pre-requisite to successful continuity of care; but although all the psychiatrists perceived the need in theory, this was not reflected in their current practice. Over half the units had some consultants who did send them, working alongside others who did not do so. There is an urgent need for all psychiatrists within a region to reach a consensus of agreement on the need for summaries and what they should contain.
It is important to identify the aims of the summary, and the advantages and disadvantages of generic $v$. psychiatric specific summaries criteria which could provide regional guidelines for content, design and use.

The findings of this survey suggest that other regions should also look at current practices relating to the use of discharge summaries. This could be the first step towards defining minimal acceptable standards of practice when psychiatric patients are discharged from hospital.

\section{Acknowledgements}

This work was made possible by a grant from the South East Thames Regional Health Authority. We are grateful to all the psychiatrists who took part in this study by responding to the questionnaire. We would also like to thank Professor Michael Healy for his advice ard help on the statistical aspects of the study.

\section{Further reading}

Essex, B. J., Dolg, R. \& Renshaw, J. (1990) Pilot study of records of shared care for people with mental illnesses. British Medical Journal, 300, 1442-1446.

HARDING, J. (1987) Study of discharge communications from hospital doctors to an inner London general practice. Journal of the Royal College of General Practitioners, 454-459.

KERR, M. S. D. (1990) Psychiatric discharge summaries. British Medical Journal, 300, 260.

OrReLl, M. W. \& GREENBERG, M. (1986) What makes psychiatric summaries useful to general practitioners? Bulletin of the Royal College of Psychiatrists, 10, 107-109.

RigbY, J. C. \& CockbURN, A. C. (1988) Psychiatric discharge summaries: an assessment of need. Practitioner. 232, 677-679.

\section{Prix van Gysel}

The van Gysel Foundation for medical research has instituted a biennial prize of 2,000,000 Belgium francs to be known as the prix van Gysel. It is aimed at promoting the development of higher teaching and research in the biomedical field. The prize was awarded for the first time in 1990 and will be awarded every other year thereafter. Further information can be obtained from Fondation van Gysel, Palais des Academies, Rue Ducale 1, 1000 Bruxelles, Belgium. 